\title{
Community-based asthma care: trial of a "credit card" asthma self-management plan
}

\author{
W. D'Souza*, J. Crane*, C. Burgess*, H. Te Karu**, C. Fox**, M. Harper**, B. Robson*, \\ P. Howden-Chapman*, L. Crossland*, K. Woodman*, N. Pearce*, E. Pomare*, R. Beasley*
}

Community-based asthma care: trial of a "credit card" asthma self-management plan. W. D'Souza, J. Crane, C. Burgess, H. Te Karu, C. Fox, M. Harper, B. Robson, P. HowdenChapman, L. Crossland, K. Woodman, N. Pearce, E. Pomare, R. Beasley. CERS Journals Ltd 1994.

ABSTRACT: Although asthma self-management plans are widely recommended as essential in the long-term treatment of adult asthma, there have been few studies examining their use. Our objective was to assess the effect of a "credit card" adult asthma self-management plan in a community experiencing major health problems from asthma, by means of a before and after intervention trial of the efficacy of the "credit card" plan, when introduced through community-based asthma clinics.

The participants were 69 Maori people with asthma. The "credit card" plan consisted of written guidelines for the self-management of asthma, based on selfassessment of asthma severity, printed on a plastic card. On one side, management guidelines were based on the interpretation of peak expiratory flow rate (PEFR) recordings, whilst the reverse side was based on symptoms. The outcome measures used were before and after comparison of markers of asthma morbidity and requirement for acute medical treatment; and a structured questionnaire assessing the acceptability and use of the credit card plan.

Following the introduction of the plan, the mean PEFR increased from 347 to $389 \mathrm{l} \cdot \mathrm{min}^{-1}$, the percentage of nights woken fell from 30.4 to $16.9 \%$, and the number of days "out of action" fell from 3.8 to $1.7 \%$. The requirements for acute medical treatment also fell during the intervention period. Most participants commented favourably on the content and usefulness of the plan. In the situation of worsening asthma, $28 \%$ of subjects found the peak flow side of the card most helpful, $7 \%$ the symptoms side, and $48 \%$ found both sides equally helpful.

The credit card asthma self-management plan, when introduced in a programme of community-based clinics, is both an effective and acceptable system for selfmanaging asthma.

Eur Respir J., 1994, 7, 1260-1265.
*Wellington Asthma Research Group, Dept of Medicine, Wellington School of Medicine, Wellington, New Zealand. **Wairarapa Maori Executive/Taiwhenua, Masterton, New Zealand.

Correspondence: W. D'Souza

Dept of Medicine

Wellington School of Medicine

PO Box 7343

Wellington South

Wellington

New Zealand

Keywords: Asthma

self-management

Received: May 51993

Accepted after revision April 111994

This study was funded by the Wellington Area Health Board, the Health Research Council of New Zealand, and the New Zealand Department of Health.
Asthma self-management plans are recommended as being essential in the long-term treatment of adult asthma [1-4]. Their importance originated from the knowledge that delays in recognizing deteriorating asthma and initiating early and appropriate therapy are important factors contributing to asthma morbidity and mortality [5]. Consequently, self-management plans focus on the early recognition of unstable or deteriorating asthma, by monitoring peak expiratory flow rate (PEFR) recordings or symptoms. Through the use of written guidelines, patients are then able to determine when it is necessary to adjust therapy or obtain medical assistance.

Despite the widespread agreement on the importance of self-management plans, few studies have examined their use. One of the first self-management plans to be assessed was based on the educated interpretation of PEFR. In an open study of adult asthmatics, the introduction and use of this PEFR-based plan led to a substantial improvement both in retrospective and cross-sectional measures of asthma severity, although it was not possible to identify which specific features of the plan were responsible for the improvement [6].

Subsequently, a self-management plan was developed in which the same management guidelines were based on the educated interpretation of symptoms. It was shown that, with intensive education and follow-up, both "peak flow" and "symptoms-based" plans result in significant reductions in acute medical treatment [7]. Although both plans showed similar benefits, it has subsequently been questioned whether the symptoms-led approach is as safe or effective when used for severe asthmatics [8].

In response to these findings, we developed a "credit card" self-management plan, which incorporated the essential features of these "peak flow" and "symptomsbased" plans. This study aimed to assess the effect of this plan in an open, prospective, before-and-after trial, involving a disadvantaged rural Maori community in New Zealand. The study was based in the Maori community 
because they have a greater morbidity and mortality from asthma than non-Maori New Zealanders, with evidence to suggest that these ethnic differences may be due to inadequate management [9-11].

\section{Methods}

\section{Participants}

The Hauora Runanga (Health Council) of the Wairarapa Maori Executive/Taiwhenua of Te Runanganui o Ngati Kahungunu took the initiative in inviting Maori people with asthma to participate in the study. By working through established community networks, asthmatics interested in enrolling in the programme were identified. Although this method did not result in a random selection of asthmatic individuals, it did ensure a good participation rate of people experiencing significant asthma morbidity.

Prior to its commencement, the nature of the programme was discussed with the general practitioners in the area. The general practitioners were also informed of each participant's involvement in the study, and notes were sent regarding their progress during, and at the conclusion, of the intervention period. The study was approved by the Wellington Area Health Board Ethics Committee.

Table 1 provides a summary of the characteristics of the 69 participants, 55 females and 14 males, with a mean age of $38 \mathrm{yrs}$, in whom a clinical diagnosis of reversible airways obstruction had been made and who were enrolled in the study. About half (54\%) of participants had no secondary school or tertiary qualifications. Participants were excluded from the analysis if they were outside the age range 14-65 yrs, or if they had other uncontrolled medical problems besides asthma.

The study participants had considerable morbidity from asthma, for example $29 \%$ reported being woken "most nights" with asthma or coughing. Their unstable asthma was also reflected in the high percentage of people (41\%) who had seen the doctor in an emergency for their asthma in the last year. Despite this, only $13 \%$ had a written management plan for use in an emergency, although half $(54 \%)$ possessed a peak flow meter.

\section{Study design}

The study involved a comparison of markers of asthma morbidity, requirement for acute medical treatment, and prescribed drug therapy before-and-after the introduction of the self-management plan. During the initial run-in period of 8 weeks, participants were given a peak flow meter (if they did not already have one), and completed daily diaries on whether they had woken from sleep with asthma or coughing, whether they had a day "out of action", and the best value from two morning prebronchodilator peak flow recordings.

Every month, they also recorded the number of occasions on which nebulized medications, courses of oral corticosteroids, hospital emergency department visits, and hospital admissions were required.

Table 1. - Characteristics of enrolled participants

\begin{tabular}{|c|c|c|c|c|c|}
\hline \multirow{3}{*}{ Use of medical services } & \multicolumn{3}{|c|}{ Age yrs } & \multirow{2}{*}{\multicolumn{2}{|c|}{$\begin{array}{c}\text { Total } \\
(\mathrm{n}=69) \\
\mathrm{n}(\%)\end{array}$}} \\
\hline & $\begin{array}{c}14-31 \\
(\mathrm{n}=25) \\
\mathrm{n}\end{array}$ & $\begin{array}{c}32-47 \\
(\mathrm{n}=22) \\
\mathrm{n}\end{array}$ & $\begin{array}{c}48-65 \\
(\mathrm{n}=22) \\
\mathrm{n}\end{array}$ & & \\
\hline & & & & & \\
\hline Visit to doctor & 17 & 17 & 20 & 54 & (78) \\
\hline $\begin{array}{l}\text { General practitioner } \\
\text { emergency visits }\end{array}$ & 5 & 9 & 14 & 28 & $(41)$ \\
\hline $\begin{array}{l}\text { Hospital emergency } \\
\text { department visits }\end{array}$ & 4 & 3 & 6 & 13 & (19) \\
\hline $\begin{array}{l}\text { Hospital admission } \\
\text { Asthma morbidity }\end{array}$ & 2 & 2 & 6 & 10 & (14) \\
\hline Woken with asthma/cough most nights & 9 & 8 & 3 & 20 & (29) \\
\hline Greater than seven days "out of action" & 4 & 4 & 7 & 15 & (22) \\
\hline Asthma management & & & & & \\
\hline Peak flow meter* & 8 & 12 & 17 & 37 & (54) \\
\hline Written management plan* & 3 & 2 & 4 & 9 & (13) \\
\hline Prescribed inhaled steroid* & 13 & 11 & 18 & 42 & (61) \\
\hline Prescribed regular oral medications: & & & & & \\
\hline Theophylline & 4 & 3 & 7 & 14 & (20) \\
\hline Beta-agonists & 1 & 0 & 4 & 5 & (7) \\
\hline Prednisone & 0 & 2 & 1 & 3 & (4) \\
\hline Ketotifen & 0 & 1 & 2 & 3 & (4) \\
\hline Socio-economic factors & & & & & \\
\hline Not employed* & 11 & 9 & 8 & 28 & (41) \\
\hline Smoker* & 13 & 13 & 6 & 32 & (46) \\
\hline
\end{tabular}

"Out of action" denotes any day spent off work or missed from school because of asthma. "Not employed" includes all those not in the labour force; retired, beneficiaries or those at home looking after children; excludes students, and full or part-time workers. *: measured at time of initial enrolment, all other measures relate to the preceding 12 months. 
Following this initial 8 week period, the self-management plan was introduced at a clinic by one of the four doctors in the study team. The participants were followed for a further 16 weeks, with a second clinic being held after 8 weeks. These clinics were held on marae (the traditional Maori community centre) in the Wairarapa area, and were organized in partnership with Maori community health workers. Throughout the study, the Maori community health workers maintained contact with the participants, encouraged them to complete their diaries and provided transport to attend the clinics if necessary.

The clinics focused on the following key points: the inflammatory basis of asthma, the use of regular inhaled steroids to reduce the frequency and severity of attacks, the use of bronchodilators for relief of symptoms or prior to known aggravating stimuli (rather than according to a regularly scheduled regime), adequate drug delivery through appropriate inhaler technique or change to drypowder or spacer delivery systems, and the recognition and appropriate self-management of unstable asthma through use of the "credit card" plan.

At the conclusion of the study, 16 weeks after the introduction of the plan, a further questionnaire was used to assess the acceptability and use of the plan. This questionnaire was structured, with both direct and openended questions, and was administered by three research assistants previously unknown to the participants.

\section{Analysis of results}

The time-frame of the study comprised three periods: one period of 8 weeks before introduction of the plan,

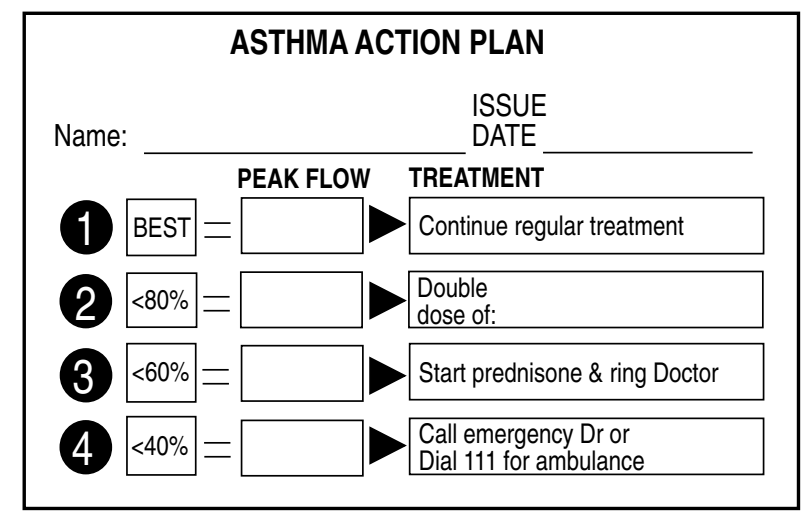

and two periods of 8 weeks after each clinic visit. Continuous measured outcomes (mean peak flow rates) were compared for the 8 week period before and the two 8 week periods after intervention by using t-tests for paired data; dichotomous measured outcomes (nights woken, days lost) were tested using standard Chi-square tests; and the outcomes involving use of acute medical care (doctor visits, hospital visits) were tested as Poisson variates [12].

Thus, for the daily and monthly measures, a comparison of asthma morbidity was made for the participants who had more than $60 \%$ of their daily recordings (peak flow, nights woken with asthma or cough, and days out of action) completed in their diaries for all periods before and after intervention.

\section{The adult asthma self-management plan}

The self-management plan provided two methods of self-assessment of asthma control: subjectively, using symptoms, and objectively with PEFR. The method for self-assessment using PEFR was printed on one side of a small plastic card, the size of a standard credit card (fig. 1 ), and the symptoms-based approach on the reverse side.

For both methods of assessment, there are four general stages in which treatment guidelines are recommended (table 2). These guidelines are based on either the development of increasingly severe symptoms or decrease in PEFR from the patient's previous "best". The best PEFR was taken as the higher of either the maximum consistent prebronchodilator PEFR recorded in the diaries, or the

Fig. 1. - The adult "credit card" asthma self-management plan.

Table 2. - Adult asthma self-management plan

\begin{tabular}{|c|c|c|c|}
\hline Step & Peak flow & Symptoms & Action \\
\hline & $80-100 \%$ best & Intermittent/few & $\begin{array}{l}\text { Continue regular inhaled anti-inflammatory treatment; take } \\
\text { bronchodilator for relief of symptoms }\end{array}$ \\
\hline 2 & $60-80 \%$ best & $\begin{array}{l}\text { Waking at night with } \\
\text { asthma or coughing }\end{array}$ & $\begin{array}{l}\text { Double the dose of inhaled anti-inflammatory treatment or } \\
\text { start if not currently taking }\end{array}$ \\
\hline 3 & $40-60 \%$ best & $\begin{array}{l}\text { Increasing breathlessness or } \\
\text { poor response to bronchodilator }\end{array}$ & Start oral corticosteroids and contact a doctor \\
\hline 4 & $<40 \%$ best & Severe attack & Call emergency doctor or ambulance urgently \\
\hline
\end{tabular}

At all stages, take inhaled bronchodilator for relief of symptoms. 
Table 3. - Markers of asthma morbidity before and after intervention with the "credit card" plan $(\mathrm{n}=47)$

\begin{tabular}{lcccr}
\hline & $\begin{array}{c}8 \text { week period } \\
\text { before }\end{array}$ & $\begin{array}{c}\text { 1st 8 week } \\
\text { period after }\end{array}$ & $\begin{array}{c}\text { 2nd 8 week } \\
\text { period after }\end{array}$ & p-value \\
\hline Peak flow $l \cdot \mathrm{min}^{-1}$ & 347 & 381 & 389 & $<0.001$ \\
Nights woken \% & 30.4 & 18.2 & 16.9 & $<0.001$ \\
Days "out of action" $\%$ & 3.8 & 3.1 & 1.7 & 0.003 \\
\hline
\end{tabular}

The p-value refers to the comparison between the period before intervention and the pooled findings for the two periods after intervention.

predicted value taken from standard tables. The "best" PEFR was modified, as appropriate, if increases in PEFR occurred following changes in the patient's treatment. For example, if the patient took a course of prednisone in accordance with the plan (PEFR less than $60 \%$ predicted), and the maximum PEFR achieved increased to greater than the predicted values, this new maximum PEFR became the "best" value.

For each stage of deterioration, clear instructions were written as to what self-management steps to take and when to seek help. These were tailored to individual patients and their requirements, and were written directly onto the card. Similarly, the patient's individual therapy, inhaled steroid or bronchodilator, and the name and telephone number of emergency help was also written onto the card. Details of the plan are provided in the Appendix.

\section{Results}

Of the 69 participants initially enrolled in the programme, 63 attended both clinics, 3 attended only the first and 3 withdrew from the programme. Of the 63 participants $(91 \%)$ who completed the programme, there were 47 (75\%) who completed a sufficient proportion of daily diaries. The other 16 participants completed the programme, but did not adequately complete more than $60 \%$ of their daily diaries. The analysis was generally restricted to this group of 47 persons, but supplementary analyses were also conducted to search for possible biases due to the noncompletion of sufficient daily diaries by the other 16 participants.

\section{Asthma morbidity}

The mean peak flow increased by $12 \%$, from 347 to $389 l \cdot \mathrm{min}^{-1}(\mathrm{p}<0.001)$, and the percentage of nights woken fell from 30.4 to $16.9 \%(\mathrm{p}<0.001)$. Very few people reported that they had days out of action, but these also fell in the final period of the study from 3.8 to $1.7 \%$ $(\mathrm{p}<0.003)$ (table 3). If the 16 patients who did not adequately complete their diaries were also included in the analysis, the overall mean peak flow increased by $9 \%$, from 357 to $390 \mathrm{l} \cdot \mathrm{min}^{-1}(\mathrm{p}<0.001)$, the percentage of nights woken fell from 28.9 to $17.1 \%(\mathrm{p}<0.001)$, and the percentage of days "out of action" fell from 3.5 to $2.3 \%(\mathrm{p}<0.05)$ for the 63 study participants.

\section{Health care utilization}

The number of occasions, per 8 week period, in which nebulized medications were used fell significantly during the study from 18 to $6(\mathrm{p}=0.023)$. There were very few asthma-related hospital emergency department visits and admissions during the study, but these also fell from 9 to $3(\mathrm{p}=0.086)($ table 4$)$.

\section{Prescribed drug therapy}

At the first clinic, 15 participants $(31 \%)$ received a course of prednisone from the clinic doctors due to a current PEFR of less than $60 \%$ predicted; this was required in only three participants $(6 \%)$ at the final clinic. The

Table 4. - Requirements for acute medical treatment before and after intervention with the "credit card" plan $(\mathrm{n}=47)$

\begin{tabular}{lcccc}
\hline & $\begin{array}{c}8 \text { week period } \\
\text { before }\end{array}$ & $\begin{array}{c}\text { 1st } 8 \text { week } \\
\text { period after }\end{array}$ & $\begin{array}{c}\text { 2nd 8 week } \\
\text { period after }\end{array}$ & p-value \\
\hline $\begin{array}{l}\text { Courses of prednisone } \\
\begin{array}{l}\text { Initiated by participant } \\
\text { general practitioner }\end{array}\end{array}$ & 14 & & 13 & 0.823 \\
$\begin{array}{l}\text { Initiated by clinic doctors } \\
\text { Hospital visits }\end{array}$ & - & 13 & 3 & \\
$\begin{array}{l}\text { Emergency department } \\
\text { Admissions }\end{array}$ & 6 & 15 & 2 & 0.136 \\
Total & 3 & 3 & 1 & 0.386 \\
Nebulizer use & 9 & 2 & 3 & 0.086 \\
\hline
\end{tabular}

The p-value refers to the comparison between the period before intervention and the pooled findings for the two periods after intervention. 
number of patient/general practitioner initiated courses of prednisone remained constant throughout the study (table 4).

The number of participants who reported that they were prescribed inhaled steroids increased from $61 \%$ (42) to 93\% (64) $(\mathrm{p}<0.001)$. Of perhaps greater health significance, is the increase from $39 \%$ (27) to $91 \%$ (63) $(\mathrm{p}<0.001)$ of participants who indicated that inhaled steroids were prescribed for regular use. The number of participants prescribed oral bronchodilators (i.e. theophyllines and beta-agonists) decreased from $32 \%$ (22) to $13 \%$ (9) $(\mathrm{p}=0.01)$.

\section{Acceptability of the "credit card" plan}

Of the 63 people who completed the programme, 55 (87\%) responded to the questions on the acceptability of the plan. Most participants commented favourably on the usefulness of the plan. Forty five participants (82\%) felt that the use of the plan had contributed to a definite overall improvement in their asthma. Of the $45(82 \%)$ participants who had a "bad attack" of asthma, 48\% reported that they found both sides of the self-management plan equally helpful, $28 \%$ found the peak flow side most helpful, $7 \%$ found the symptom side most helpful, whilst $17 \%$ "didn't know". With regard to the plan's content, $47(86 \%)$ disagreed with the statement that it should be bigger, $47(86 \%)$ considered that it presented enough detail, and $52(94 \%)$ disagreed with the statement that the instructions were difficult to follow.

During the final three months of the study, 33 (60\%) participants reported that they had initiated an increase in the amount of their inhaled steroids according to the instructions on the "credit card" plan. Among 25 (46\%) participants who received a course of prednisone following institution of the plan, $11(44 \%)$ had self-initiated their last course, and $14(56 \%)$ had their last course initiated by the clinic doctors (11) or general practitioners (3).

\section{Discussion}

In this open, prospective study we have found that the credit card asthma self-management plan is both an effective and acceptable system for self-managing asthma, when introduced into a programme of community-based clinics. This was reflected primarily by improvement in measures of asthma morbidity, such as peak expiratory flow rates and nights woken with asthma or coughing. There was also a reduction in the requirement for acute medical treatment, indicated by a decrease in emergency department hospital visits, hospital admissions and requirements for nebulized medications, although the small numbers involved meant that not all of these differences were statistically significant. The participants commented favourably on the plan, and in particular, that is was simple and easy to follow.

There are a number of reasons why it is necessary to be cautious before attributing the improvement in asthma morbidity to the use of the "credit card" plan. In particular, it could be argued that the programme of specialist community-based clinics may have led to a significant improvement in asthma control, which was independent of that due to the plan. However, we would suggest that the careful and thorough introduction of the plan with appropriate explanation should be considered as a vital element in the overall management programme.

We had initially hoped to include a control group of participants, who would be included in the programme of clinics but would not receive the plan. However, we were advised that a control group of this type would not succeed in the close-knit Wairarapa Maori community, due to discussion and sharing of the plan throughout the community.

Another consideration is whether a 4 month intervention period is too short to ascribe meaningful longterm significance to the measured outcomes. Whilst we would have preferred a longer follow-up period, this would probably have led to a reduced compliance in diary recordings, making assessment of the outcome difficult. Although it is possible that the improvement would diminish with time, there was no evidence from our data to suggest that this was occurring during the study period. In fact, there was a trend towards further improvement during the final intervention period.

The omission of 16 participants from the primary analysis had the potential to lead to an over-estimation of the benefits of the plan (i.e. those participants who deteriorated while using the plan stopped completing their diaries). However, further analysis of this subgroup showed little evidence for this, with these 16 participants showing a similar magnitude of improvement in measured outcomes of asthma morbidity. Also, all 16 attended both clinics, further supporting the view that they did not represent a drop-out group.

It is not possible from this study to determine what specific features of the programme led to the reduction in asthma morbidity. The greater use of regular inhaled corticosteroid treatment, in accordance with current national and international guidelines [1-4], undoubtedly contributed to the observed improvement [13]. The prescription of a course of oral corticosteroids for about a third of participants at the first clinic (for patients with a PEFR below $60 \%$ of their predicted best values) is likely to have led to an initial improvement, although the further clinical benefit observed in the second 8 week intervention period is not explained by increased prednisone use, as this fell to levels similar to those before the plan was introduced. Other probable factors include the better understanding of asthma and its management [14], review of asthma control and inhaler technique, encouragement in self-management based on objective assessment of lung function, longer more informal clinic visits and the community-based approach to health care delivery. However, all of these factors should be considered as essential elements of any asthma management plan.

Although there is a well recognized tendency for patients to comment favourably on new health initiatives, irrespective of their objective value, the positive comments about the credit card plan are of interest. Most felt that 
the plan was simple and easy to follow, and that it had led to an overall improvement in their asthma. Almost all of the participants considered that the plan should not be bigger or present more detail, suggesting that more complicated plans may be less suitable for general use.

We did not directly assess which side of the plan was most useful, although the participant's preference in the situation of a "bad attack" of asthma was recorded. Although the PEFR side was preferred more than the symptom side, most participants indicated that they found both sides equally helpful. These findings not only reinforce the importance of objective assessment of asthma during acute exacerbations, but also suggest that patients should be offered both PEFR and symptoms-based methods of assessment.

We conclude that, when introduced as part of a programme of community-based asthma clinics, the use of the "credit card" asthma self-management plan results in a reduction in asthma morbidity in a community experiencing major health problems from asthma.

Acknowledgements: The authors are particularly grateful to the participants in the programme, and to the Marae committees of Tuhirangi Marae, Hauariki Marae, Papawai Marae, Ngawaka, Te Hepara Pai Marae, Te Kapua o te Rangi Marae, and Te Ore Ore Marae. They also wish to thank L. Dyall, C. Wineera and K. Poutasi (Wellington Area Health Board), T. Gemmell, The Wairarapa Maori Executive/Taiwhenua o Ngati Kahungunu Ki Wairarapa, H. Tutengaehe, M. Hight, Te Uira Keefe, I. Ramsden, E. Tuuta, L. Kerse, I. Da Costa, L. Beckwith, the late Reverend O. Robinson and R. Peritini (Wellington Area Health Board Ethics Committee), M. Tunks and K. Witten (Health Research Council), and the warm hospitality of the many community groups and individuals who hosted us during the study. The Wellington Asthma Research Group is funded by a Programme Grant for the Health Research Council of New Zealand. N.P and J.C are funded by Senior Fellowships of the Health Research Council of New Zealand, and W. D'S was funded by a Research Fellowship from the Asthma Foundation of New Zealand.

\section{Appendix 1}

\section{Asthma self-management with the "credit card" plan}

1. If a person has few symptoms and their PEFR was greater than $80 \%$ of "best" (Step 1 on the plan), they were instructed to take their regular treatment, which usually consisted of inhaled steroids taken twice daily, and inhaled beta-agonist as required for relief of symptoms. 2. If a person was waking up at night with asthma or their PEFR was less than $80 \%$ of "best" (Step 2 on the plan), they were instructed to double their dose of inhaled steroid, for the number of days required to reach Step 1, to continue this increased dose for the same number of days, and then return to their previous maintenance dose. 3. If a person was experiencing increasing breathlessness, a poor response to their bronchodilator, or their PEFR was less than $60 \%$ of "best" (Step 3 on the plan), they were instructed to start their home supply of oral prednisone, 30-40 mg daily, and contact their general practitioner. Prednisone was continued at this dose for the number of days required to reach Step 1, then reduced to 15-20 mg daily for the same number of days before stopping. 4. If, despite these actions, the attack of asthma became even more severe, and the PEFR fell to less than $40 \%$ of "best" (Step 4 on the plan), the person was instructed to seek emergency medical help immediately.

\section{References}

1. British Thoracic Society. Guidelines for management of asthma in adults. I. Chronic persistent asthma. $\mathrm{Br} \mathrm{Med}$ $J$ 1990; 301: 651-653.

2. Thoracic Society of Australia and New Zealand. Consensus on asthma: asthma management plan, 1989. Med J Aust 1989; 18: 650-658.

3. Hargreave FE, Dolovich J, Newhouse MT (eds). The assessment and treatment of asthma. a conference report. J Allergy Clin Immunol 1990; 85: 1098-1111.

4. Guidelines for the diagnosis and management of asthma: National Heart, Lung and Blood Institute, National Asthma Education Program Expert Panel report. J Allergy Clin Immunol 1991; 88: 425-534.

5. Rea HH, Sears MR, Beaglehole R, et al. Lessons from the national asthma mortality study: circumstances surrounding death. NZ Med J 1987; 100: 10-13.

6. Beasley R, Cushley M, Holgate ST. A self-management plan in the treatment of adult asthma. Thorax 1989; 44: 200-204.

7. Charlton I, Charlton G, Broomfield J, Mullee MA. Evaluation of peak flow and symptoms only self-management plans for control of asthma in general practice. $\mathrm{Br}$ Med J 1990; 301: 1355-1359.

8. Braddick MR. Self-management of asthma (Letter). $\mathrm{Br}$ Med J 1991; 302: 348

9. Sears MR, Rea HH, Beaglchole R, et al. Asthma mortality in New Zealand: a two year national study. NZ Med J 1985; 98: 271-275.

10. Pomare EW, de Boer GM. Hauora: Maori standards of health, 1970-1984. Wellington, Department of Health, 1988.

11. Pomare E, Tutengaehe H, Ramsden I, Hight M, Pearce $\mathrm{N}$, Ormsby V. He Mate Huango. Maori Asthma Review. Report to the Minister of Maori Affairs from the review team to consider asthma among Maori people. Wellington, Huia Publications, 1991.

12. Armitage P, Berry G. Statistical methods in medical research. Oxford, Blackwell, 1987.

13. Salmeron S, Guerin JC, Godard P, et al. High doses of inhaled corticosteroids in unstable chronic asthma: a multicenter, double-blind, placebo-controlled study. Am Rev Respir Dis 1989; 140: 167-171.

14. Bolton MM, Tilley BC, Kuder J, Reeves T, Schultz LR. The cost and effectiveness of an education program for adults who have asthma. J Gen Intern Med 1991; 6: 401-407. 